\title{
Laissez-faire versus Pareto
}

\section{Kristof Bosmans $^{1}\left[\right.$ [D $\cdot$ Z. Emel Öztürk ${ }^{2}$ (C)}

Received: 25 March 2019 / Accepted: 22 October 2021 / Published online: 8 November 2021

(c) The Author(s) 2021

\begin{abstract}
Consider two principles for social evaluation. The first, "laissez-faire", says that mean-preserving redistribution away from laissez-faire incomes should be regarded as a social worsening. This principle captures a key aspect of libertarian political philosophy. The second, weak Pareto, states that an increase in the disposable income of each individual should be regarded as a social improvement. We show that the combination of the two principles implies that total disposable income ought to be maximized. Strikingly, the relationship between disposable incomes and laissez-faire incomes must therefore be ignored, leaving little room for libertarian values.
\end{abstract}

\section{Introduction}

Libertarianism attributes ethical value to laissez-faire outcomes. Not in the name of efficiency or welfare maximization, but in the name of individual freedom and rights. Proponents of this political philosophy accordingly regard redistributive taxation as inherently injust. Famously, Nozick (1974, p. 169) states that "[t]axation of earnings from labor is on a par with forced labor.... taking the earnings of $n$ hours labor is like taking $n$ hours from the person; it is like forcing the person to work

We thank Bart Capéau, Marc Fleurbaey, Jean-Jacques Herings, François Maniquet, Erwin Ooghe and Erik Schokkaert for useful comments. All remaining shortcomings are ours.

Z. Emel Öztürk

z.e.ozturk@tilburguniversity.edu

Kristof Bosmans

k.bosmans@maastrichtuniversity.nl

1 Department of Microeconomics and Public Economics, Maastricht University, Tongersestraat 53, 6211 LM Maastricht, The Netherlands

2 Department of Economics, Tilburg University, 5000 LE Tilburg, The Netherlands 
$n$ hours for another's purpose." Similarly, Rothbard (1973, p. 85) argues that "the entire system of taxation is a form of involuntary servitude. ... [p]art of the essence of slavery, after all, is forced work for someone at little or no pay." ${ }^{1}$

Disapproval of redistribution is not exclusive to libertarianism. It also figures as a component in the influential statements of liberal egalitarianism by Arneson (1989) and Cohen (1989). ${ }^{2}$ They argue that only inequalities for which individuals cannot be held responsible require redistribution. That is, redistribution ought to end where responsibility begins. As Arneson (1990, p. 176) puts it, "distributive justice does not recommend any intervention by society to correct inequalities that arise through the voluntary choice or fault of those who end up with less, so long as it is proper to hold the individuals responsible for the voluntary choice or faulty behavior that gives rise to the inequalities."

We introduce a "laissez-faire" principle to capture the ethical role for laissez-faire outcomes. To do so, we distinguish between an individual's "market income" without government intervention and her "disposable income" after government intervention. Consider a social state in which disposable incomes coincide with market incomes. The laissez-faire principle simply says that redistribution that moves disposable incomes away from market incomes (while preserving total income) results in a socially worse social state.

We show that the laissez-faire principle, when combined with the Pareto principle, puts strong demands on the social ranking. According to the "weak Pareto" principle, an increase in the disposable income (which we assume to measure utility) of every individual is a social improvement. Our main result says that a social ranking satisfies laissez-faire and weak Pareto only if it maximizes total disposable income (Theorem 1). That is, with the exception of comparisons involving equal total disposable incomes, the social ranking must ignore distributional considerations altogether. The result is striking, as it is counter to treating the relationship between disposable incomes and market incomes as intrinsically important. We further show that there is no social ranking that satisfies the laissez-faire principle and the "Pareto indifference" principle (Theorem 2).

We provide a threefold discussion of our results. First, we clarify the relationship of our results with claims in the literature that identify Pareto indifference with a form of welfarism. This clarification is in order, as the laissez-faire principle with its reference to market incomes is clearly non-welfarist. Second, we show that the laissez-faire principle underlies the equal sacrifice principle of taxation. Our results thus allow us to draw conclusions on the extent to which the latter principle can be combined with Paretian considerations. Third, we show that our results bring to light a surprising link between the liberal reward principle, which formalizes the above-mentioned contra-redistributive idea of Arneson (1989) and Cohen (1989), and its rival principle of utilitarian reward. The intimate relationship of the laissezfaire principle with the equal sacrifice and liberal reward principles shows that our results are relevant also beyond the realm of libertarianism.

\footnotetext{
1 See Huemer (2018) for a recent libertarian case against redistribution.

2 Their work builds on the foundations laid by Rawls (1971, 1982) and Dworkin (1981a, b).
} 
Our results reveal a strong tension between the laissez-faire principle and the Pareto principle. This poses a clear challenge for the important task of incorporating libertarian and liberal egalitarian values into the standard "Paretian" economic framework for social evaluation.

\section{Results}

The set of individuals is $N=\{1,2, \ldots, n\}$. For each individual $i$ in $N$, the real number $x_{i}$ denotes her disposable income (after government intervention) and the real number $m_{i}$ denotes her market income (without government intervention). ${ }^{3}$ Let $x=\left(x_{1}, x_{2}, \ldots, x_{n}\right)$ and $m=\left(m_{1}, m_{2}, \ldots, m_{n}\right)$. We refer to a pair $(x, m)$ as a social state. ${ }^{4}$ The set $S=\mathbb{R}^{n} \times \mathbb{R}^{n}$ collects all social states. We assume that each individual ranks the social states in $S$ in accordance with her own disposable income. That is, individual $i$ in $N$ weakly prefers social state $(x, m)$ to social state $\left(x^{\prime}, m^{\prime}\right)$ if and only if $x_{i} \geq x_{i}^{\prime}$.

The aim is to compare social states on the basis of social welfare. A social ranking $R$ is a reflexive and transitive binary relation in $S$. The asymmetric and symmetric parts of $R$ ("is at least as good as") are denoted by $P$ ("is better than") and $I$ ("is equally good as").

We impose two principles on the social ranking. The first principle expresses respect for laissez-faire outcomes. Consider a social state that gives each individual a disposable income equal to her market income. Laissez-faire demands that any redistribution (that preserves total disposable income) be regarded as a social worsening.

Laissez-faire For all social states $(x, m)$ and $\left(x^{\prime}, m\right)$ in $S$ such that $\sum_{i} x_{i}=\sum_{i} x_{i}^{\prime}=\sum_{i} m_{i}$, if $x=m$ and $x^{\prime} \neq m$, then $(x, m) P\left(x^{\prime}, m\right)$.

The second principle is a weak form of the Pareto principle. Weak Pareto requires that an increase in the disposable income of every individual be regarded as a social improvement.

Weak Pareto For all social states $(x, m)$ and $\left(x^{\prime}, m^{\prime}\right)$ in $S$, if $x_{i}>x_{i}^{\prime}$ for each $i$ in $N$, then $(x, m) P\left(x^{\prime}, m^{\prime}\right)$.

Our main result says that the combination of laissez-faire and weak Pareto forces the social ranking to maximize total disposable income.

\footnotetext{
${ }^{3}$ Because of individual responses to government intervention, incomes "before" intervention need not coincide with incomes "without" intervention. The latter are the ones relevant for our purpose.

${ }^{4}$ For a social state $(x, m)$, we allow total disposable income $\sum_{i} x_{i}$ to be greater than, equal to or smaller than total market income $\sum_{i} m_{i}$. Note that the proofs of Theorems 1 and 2 still work if we impose, for each social state $(x, m)$, that $\sum_{i} x_{i}=\sum_{i} m_{i}$.
} 
Theorem 1 If a social ranking $R$ satisfies laissez-faire and weak Pareto, then, for all social states $(x, m)$ and $\left(x^{\prime}, m^{\prime}\right)$ in $S$,

$$
\sum_{i} x_{i}>\sum_{i} x_{i}^{\prime} \text { implies }(x, m) P\left(x^{\prime}, m^{\prime}\right) .
$$

Proof Let $R$ satisfy laissez-faire and weak Pareto. Let $(x, m)$ and $\left(x^{\prime}, m^{\prime}\right)$ be social states in $S$ such that $\sum_{i} x_{i}>\sum_{i} x_{i}^{\prime}$. We have to show that $(x, m) P\left(x^{\prime}, m^{\prime}\right)$. Let $1_{n}$ be the $n$-vector with a one at each entry.

Assume first that there is a positive real number $\mu$ such that $x=x^{\prime}+\mu 1_{n}$. Then we have $(x, m) P\left(x^{\prime}, m^{\prime}\right)$ by weak Pareto.

Assume next that there is no positive real number $\mu$ such that $x=x^{\prime}+\mu 1_{n}$. Let $\delta$ be the positive real number for which $\sum_{i} x_{i}-\sum_{i} x_{i}^{\prime}=2 \delta n$.

By weak Pareto, we have

$$
(x, m) P\left(x-\delta 1_{n}, x-\delta 1_{n}\right) .
$$

Note that $\sum_{i}\left(x_{i}-\delta\right)=\sum_{i}\left(x_{i}^{\prime}+\delta\right)$ and, by the above assumption, $x-\delta 1_{n} \neq x^{\prime}+\delta 1_{n}$. Hence, by laissez-faire, we have

$$
\left(x-\delta 1_{n}, x-\delta 1_{n}\right) P\left(x^{\prime}+\delta 1_{n}, x-\delta 1_{n}\right) .
$$

By weak Pareto, we have

$$
\left(x^{\prime}+\delta 1_{n}, x-\delta 1_{n}\right) P\left(x^{\prime}, m^{\prime}\right) .
$$

Using transitivity, we obtain $(x, m) P\left(x^{\prime}, m^{\prime}\right)$.

We provide an example to show that there exist social rankings that satisfy laissez-faire and weak Pareto.

Example 1 For each social state $(x, m)$ in $S$, let $v(x-m)$ denote the variance of the vector $x-m=\left(x_{1}-m_{1}, x_{2}-m_{2}, \ldots, x_{n}-m_{n}\right)$. Let $R$ be the social ranking such that, for all social states $(x, m)$ and $\left(x^{\prime}, m^{\prime}\right)$ in $S$, we have that (i) if $\sum_{i} x_{i}>\sum_{i} x_{i}^{\prime}$, then $(x, m) P\left(x^{\prime}, m^{\prime}\right)$ and (ii) if $\sum_{i} x_{i}=\sum_{i} x_{i}^{\prime}$, then $(x, m) R\left(x^{\prime}, m^{\prime}\right)$ if and only if $v(x-m) \leq v\left(x^{\prime}-m^{\prime}\right)$. The social ranking $R$ satisfies laissez-faire and weak Pareto. Note, incidentally, that $R$ is moreover complete.

Laissez-faire and weak Pareto are surprisingly demanding if imposed jointly on a social ranking. Comparisons of social states with different total disposable incomes must be made solely on the basis of total disposable income. In all such comparisons, the social ranking must therefore ignore the relationship between disposable incomes and market incomes. ${ }^{5}$

\footnotetext{
${ }^{5}$ We sketch how the result extends to a setting with multiple commodities. For each individual $i$ in $N$, redefine $x_{i}$ and $m_{i}$ to be, respectively, $i$ 's consumed commodity bundle and market commodity bundle in $X=\mathbb{R}^{m}$. Let $R_{i}$ denote individual $i$ 's preference relation defined on the set of consumed commodity bundles $X$. We assume that $R_{i}$ is complete, transitive, continuous and strictly monotonic, and use $P_{i}$ to denote its asymmetric part. The set $S=X^{n} \times X^{n}$ collects all social states and $R$ is a social ranking in $S$. In this setting, weak Pareto is defined as follows: for all social states $(x, m)$ and $\left(x^{\prime}, m^{\prime}\right)$ in $S$, if $x_{i} P_{i} x_{i}^{\prime}$ for
} 
Proponents of libertarianism may find this implication hard to swallow. They may reject, for example, a policy that only marginally increases total disposable income, but at the cost of a major shift of disposable incomes away from market incomes.

Example 2 Assume that there are two individuals. Let $(x, m)$ be such that $x=m=(0,100)$ and let $\left(x^{\prime}, m\right)$ be such that $x^{\prime}=(100+\varepsilon, 0)$ with $\varepsilon>0$. It is clear that in social state $\left(x^{\prime}, m\right)$ the disposable incomes and market incomes are far apart. A mild extension of laissez-faire would be that $(x, m)$ should be socially preferred to $\left(x^{\prime}, m\right)$ for some small $\varepsilon>0$. But Theorem 1 says that $\left(x^{\prime}, m\right) P(x, m)$ for each $\varepsilon>0$.

Next, we consider the implications of strengthening weak Pareto. The "full" Pareto principle is usually defined as the combination of strong Pareto and Pareto indifference. Strong Pareto demands that if the disposable income of at least one individual increases and the disposable income of no individual decreases, then this be deemed a social improvement.

Strong Pareto For all social states $(x, m)$ and $\left(x^{\prime}, m^{\prime}\right)$ in $S$, if $x_{i} \geq x_{i}^{\prime}$ for each $i$ in $N$ with at least one strict inequality, then $(x, m) P\left(x^{\prime}, m^{\prime}\right)$.

Pareto indifference requires that if each individual is indifferent between two social states, i.e., has the same disposable income in both, then these two social states be regarded as socially equally good.

Pareto indifference For all social states $(x, m)$ and $\left(x^{\prime}, m^{\prime}\right)$ in $S$, if $x_{i}=x_{i}^{\prime}$ for each $i$ in $N$, then $(x, m) I\left(x^{\prime}, m^{\prime}\right)$.

A direct implication of Theorem 1 is that the combination of laissez-faire and weak Pareto implies strong Pareto.

Corollary 1 If a social ranking $R$ satisfies laissez-faire and weak Pareto, then $R$ satisfies strong Pareto.

Pareto indifference cannot, however, be combined with laissez-faire. Hence, a social ranking that satisfies laissez-faire must violate the full Pareto principle.

Theorem 2 There is no social ranking that satisfies laissez-faire and Pareto indifference.

Footnote 5 (continued)

each $i$ in $N$, then $(x, m) P\left(x^{\prime}, m^{\prime}\right)$. Laissez-faire becomes: for all social states $(x, m)$ and $\left(x^{\prime}, m\right)$ in $S$ such that $\sum_{i} x_{i}=\sum_{i} x_{i}^{\prime}=\sum_{i} m_{i}$ and $x_{i} P_{i} x_{i}^{\prime}$ for some $i$ in $N$, if $x=m$ and $x^{\prime} \neq m$, then $(x, m) P\left(x^{\prime}, m\right)$. The additional condition that there be at least one individual who prefers $(x, m)$ to $\left(x^{\prime}, m\right)$ prevents a direct clash with weak Pareto. For two commodity bundles $y$ and $y^{\prime}$ in $X$, we write $y>y^{\prime}$ if $y$ is greater than $y^{\prime}$ for some commodity and is no less for any other. We obtain the following extension of Theorem 1: if a social ranking $R$ satisfies laissez-faire and weak Pareto, then, for all social states $(x, m)$ and $\left(x^{\prime}, m^{\prime}\right)$ in $S$ such that $x_{i} P_{i} x_{i}^{\prime}$ for some $i$ in $N$, we have that $\sum_{i} x_{i}>\sum_{i} x_{i}^{\prime}$ implies $(x, m) P\left(x^{\prime}, m^{\prime}\right)$. 
Proof The proof is by contradiction. Assume that $R$ is a social ranking that satisfies laissez-faire and Pareto indifference.

Let $x$ and $x^{\prime}$ in $\mathbb{R}^{n}$ be such that $\sum_{i} x_{i}=\sum_{i} x_{i}^{\prime}$ and $x \neq x^{\prime}$. We have $\left(x, x^{\prime}\right) I(x, x)$ by Pareto indifference, $(x, x) P\left(x^{\prime}, x\right)$ by laissez-faire and $\left(x^{\prime}, x\right) I\left(x^{\prime}, x^{\prime}\right)$ by Pareto indifference. Using transitivity, we obtain $\left(x, x^{\prime}\right) P\left(x^{\prime}, x^{\prime}\right)$. But we have $\left(x^{\prime}, x^{\prime}\right) P\left(x, x^{\prime}\right)$ by laissez-faire.

The next section discusses Theorems 1 and 2 in the light of earlier literature. We show how our results relate to the result by Kaplow and Shavell (2001) on the incompatibility between non-welfarist principles and the Pareto principle. We further connect laissez-faire with the equal sacrifice and liberal reward principles.

\section{Discussion}

\subsection{Welfarism and Pareto}

Kaplow and Shavell (2001) provide a result which they interpret as stating that a social ranking "that is not purely welfarist violates the Pareto principle" (p. 284). Their result has several ingredients in common with Theorems 1 and 2. First, the result by Kaplow and Shavell involves weak Pareto and Pareto indifference, which they equate with "the Pareto principle" and "welfarism", respectively. Second, their result makes a claim about non-welfarist principles. Clearly, laissez-faire is a nonwelfarist principle, as it renders the social ranking of social states dependent on the non-utility information, viz., the market incomes, in those social states.

For clarity, we restate and prove the result by Kaplow and Shavell (2001) in our setting. We first define continuity, which demands that small changes in a social state only cause small changes in its social ranking relative to other social states.

Continuity For all social states $(x, m)$ and $\left(x^{\prime}, m^{\prime}\right)$ in $S$, if a sequence $\left\{x^{k}\right\}_{k \in \mathbb{N}}$ converges to $x$ and we have $\left(x^{k}, m\right) R\left(x^{\prime}, m^{\prime}\right)$ [respectively, $\left(x^{\prime}, m^{\prime}\right) R\left(x^{k}, m\right)$ ] for each $k$ in $\mathbb{N}$, then $(x, m) R\left(x^{\prime}, m^{\prime}\right)$ [respectively, $\left.\left(x^{\prime}, m^{\prime}\right) R(x, m)\right]$.

What the Kaplow-Shavell result in fact establishes is that continuity and weak Pareto imply Pareto indifference. ${ }^{6}$ Note that our proof of the result does not assume the completeness of the social ranking, does not use its transitivity and only uses upper continuity. ${ }^{7}$

Proposition 1 If a social ranking $R$ satisfies continuity and weak Pareto, then $R$ satisfies Pareto indifference.

\footnotetext{
6 See Suzumura (2001) for more relationships between various versions of the Pareto principle.

7 Campbell and Kelly (2002, pp. 80-81) similarly mention that the proof of Kaplow and Shavell does not use transitivity and does not require full continuity.
} 
Proof Let $R$ satisfy continuity and weak Pareto. Let $(x, m)$ and $\left(x^{\prime}, m^{\prime}\right)$ be such that $x=x^{\prime}$. We have to show that $(x, m) I\left(x^{\prime}, m^{\prime}\right)$.

Consider the sequences $\left\{x+\frac{1}{k} 1_{n}\right\}_{k \in \mathbb{N}}$ and $\left\{x^{\prime}+\frac{1}{k} 1_{n}\right\}_{k \in \mathbb{N}}$. By weak Pareto, we have $\left(x+\frac{1}{k} 1_{n}, m\right) R\left(x^{\prime}, m^{\prime}\right)$ and $\left(x^{k}+\frac{1}{k} 1_{n}, m^{\prime}\right) R(x, m)$ for each $k$ in $\mathbb{N}$. Using continuity, we obtain $(x, m) R\left(x^{\prime}, m^{\prime}\right)$ and $\left(x^{\prime}, m^{\prime}\right) R(x, m)$. That is, $(x, m) I\left(x^{\prime}, m^{\prime}\right)$.

We now discuss the relationship between our results and Proposition 1. First, from the combination of Proposition 1 and Theorem 2 it follows that adding continuity to the axioms in Theorem 1 produces an impossibility. There do exist social rankings that satisfy weak Pareto and laissez-faire, as Example 1 shows, but none of these social rankings satisfies continuity.

Second, Proposition 1 shows that what Kaplow and Shavell (2001) have established is essentially a connection between two components of the full Pareto principle. That Pareto indifference furthermore clashes with non-welfarist principles is not immediate. As Weymark (2017, Theorem 1) shows, the equivalence between Pareto indifference and (single-profile) welfarism is non-trivial and requires the transitivity of the social ranking. ${ }^{8}$ The proof of Theorem 2 echoes Weymark's insight, as it establishes the clash between Pareto indifference and laissez-faire by use of transitivity. ${ }^{9}$

\subsection{Equal sacrifice}

Suppose that total market income is at least as great as total disposable income and interpret the difference as the tax burden. A question that arises is how to divide the tax burden among the individuals.

The equal sacrifice principle says that a division of the tax burden in which all individuals incur the same utility loss is socially better than a division in which some individuals lose more than others. ${ }^{10}$ Let $u: \mathbb{R} \rightarrow \mathbb{R}$ be an increasing function, to be interpreted as the common utility function.

Equal sacrifice For all social states $(x, m)$ and $\left(x^{\prime}, m\right)$ in $S$ such that $\sum_{i} x_{i}=\sum_{i} x_{i}^{\prime} \leq \sum_{i} m_{i}$, if $u\left(x_{i}\right)-u\left(m_{i}\right)=u\left(x_{j}\right)-u\left(m_{j}\right)$ for all $i$ and $j$ in $N$ and $u\left(x_{i}^{\prime}\right)-u\left(m_{i}\right) \neq u\left(x_{j}^{\prime}\right)-u\left(m_{j}\right)$ for some $i$ and $j$ in $N$, then $(x, m) P\left(x^{\prime}, m\right)$.

\footnotetext{
${ }^{8}$ Single-profile welfarism requires that there exist a binary relation in utility space that represents the social ranking for a fixed profile of individual utility functions. Multi-profile welfarism requires that there exists a single such binary relation for all profiles of individual utility functions. This distinction is key in the debate between Kaplow and Shavell $(2001,2004)$ and Fleurbaey et al. (2003), with the former defending the single-profile version and the latter the multi-profile version of welfarism. See Suzumura (2011, p. 675) and Weymark (2017, p. 292) for further commentary.

${ }^{9}$ Let $x$ and $x^{\prime}$ in $\mathbb{R}^{n}$ be such that $\sum_{i} x_{i}=\sum_{i} x_{i}$ and $x \neq x^{\prime}$. For a social ranking $R$ that satisfies single-profile welfarism, we have $(x, x) P\left(x^{\prime}, x\right)$ if and only if $\left(x, x^{\prime}\right) P\left(x^{\prime}, x^{\prime}\right)$. The clash with laissez-faire is immediate and does not require the transitivity of $R$.

${ }^{10}$ The equal sacrifice principle was first proposed by J. S. Mill (1909, Book V, Chapter II). See Musgrave (1959, Chapter 5) for a historical account. For modern examinations of the principle, see, e.g., Young $(1987,1988,1990)$ and Weinzierl (2014).
} 
Equal sacrifice favors taxation that preserves the utility differences associated with the market income distribution. This non-redistributive preference is clearly in the spirit of laissez-faire. It is no surprise, therefore, that equal sacrifice implies laissez-faire. $^{11}$

Proposition 2 If a social ranking $R$ satisfies equal sacrifice, then $R$ satisfies laissez-faire.

Proof Let $R$ satisfy equal sacrifice. Let $(x, m)$ and $\left(x^{\prime}, m\right)$ in $S$ be such that $\sum_{i} x_{i}=\sum_{i} x_{i}^{\prime}=\sum_{i} m_{i}, x=m$ and $x^{\prime} \neq m$. We have to show that $(x, m) P\left(x^{\prime}, m\right)$.

Because $x=m$, we have $u\left(x_{i}\right)-u\left(m_{i}\right)=u\left(x_{j}\right)-u\left(m_{j}\right)=0$ for all $i$ and $j$ in $N$. Because $x^{\prime} \neq m$ and $\sum_{i} x_{i}^{\prime}=\sum_{i} m_{i}$, there must exist $i$ and $j$ in $N$ such that $x_{i}^{\prime}-m_{i}>0>x_{j}^{\prime}-m_{j}$, and, hence, $u\left(x_{i}^{\prime}\right)-u\left(m_{i}\right)>0>u\left(x_{j}^{\prime}\right)-u\left(m_{j}\right)$. Using equal sacrifice, we obtain $(x, m) P\left(x^{\prime}, m\right)$.

From the combination of Proposition 2 and Theorem 1 it follows that equal sacrifice and weak Pareto force the social ranking to maximize total post-tax income. The following example, a simple variation on Example 1, shows that there exist social rankings that satisfy equal sacrifice and weak Pareto.

Example 3 For each social state $(x, m)$ in $S$, let $v(u(x)-u(m))$ denote the variance of the vector $\left(u\left(x_{1}\right)-u\left(m_{1}\right), u\left(x_{2}\right)-u\left(m_{2}\right), \ldots, u\left(x_{n}\right)-u\left(m_{n}\right)\right)$. Let $R$ be the social ranking such that, for all social states $(x, m)$ and $\left(x^{\prime}, m^{\prime}\right)$ in $S$, we have that (i) if $\sum_{i} x_{i}>\sum_{i} x_{i}^{\prime}$, then $(x, m) P\left(x^{\prime}, m^{\prime}\right)$ and (ii) if $\sum_{i} x_{i}=\sum_{i} x_{i}^{\prime}$, then $(x, m) R\left(x^{\prime}, m^{\prime}\right)$ if and only if $v(u(x)-u(m)) \leq v\left(u\left(x^{\prime}\right)-u\left(m^{\prime}\right)\right)$. The social ranking $R$ satisfies equal sacrifice and strong Pareto. Note, incidentally, that $R$ is complete and violates continuity and Pareto indifference.

We end with a remark analogous to that regarding Example 2. The scope to further strengthen equal sacrifice is severely limited. Even a mild strengthening that recommends foregoing an arbitrarily small amount of total disposable income in exchange for a substantial reduction in the inequality of individual utility sacrifices would clash with weak Pareto.

\subsection{Liberal and utilitarian reward}

Imagine that an individual's market income is determined by ethically arbitrary circumstance characteristics (e.g., parental background) as well as ethically significant responsibility characteristics (e.g., work effort). Then two principles emerge. First, the principle of compensation, which imposes aversion to the income inequalities

\footnotetext{
11 This does not mean that libertarians endorse equal sacrifice taxation. For example, Rothbard (1977, p. 151) after observing that the principle "asks that equal hurt be imposed on all" concludes that "[a]s a criterion of justice, this is as untenable as asking for equal slavery."
} 
caused by differences in circumstances. Second, the principle of reward, which calls for an absence of aversion to the income inequalities due to differences in the exercise of responsibility. As we are only interested in the principle of reward here, we assume that all individuals have identical circumstances and, therefore, differ only with respect to responsibility. ${ }^{12}$

The principle of reward comes in two rival forms, liberal and utilitarian reward, each of which gives a different meaning to the idea of "absence of inequality aversion".

Liberal reward demands that the inequalities present in the market income distribution be respected. ${ }^{13}$ It says that, for a given market income distribution, the division of total disposable income that exhibits the same pairwise income inqualities as does the market income distribution is socially preferable to other divisions of the total.

Liberal reward For all social states $(x, m)$ and $\left(x^{\prime}, m\right)$ in $S$ such that $\sum_{i} x_{i}=\sum_{i} x_{i}^{\prime}$, if $x_{i}-x_{j}=m_{i}-m_{j}$ for all $i$ and $j$ in $N$ and $x_{i}^{\prime}-x_{j}^{\prime} \neq m_{i}-m_{j}$ for some $i$ and $j$ in $N$, then $(x, m) P\left(x^{\prime}, m\right)$.

Utilitarian reward requires that the social ranking be inequality neutral. ${ }^{14}$ In other words, the social ranking should maximize total disposable income. We formulate a version of utilitarian reward that applies only to the asymmetric part of the social ranking.

Utilitarian reward For all social states $(x, m)$ and $\left(x^{\prime}, m^{\prime}\right)$ in $S$, we have that $\sum_{i} x_{i}>\sum_{i} x_{i}^{\prime}$ implies $(x, m) P\left(x^{\prime}, m^{\prime}\right)$.

It is immediate that liberal reward implies laissez-faire. ${ }^{15}$ The combination of this implication and Theorem 1 yields the simple but striking result that the liberal reward principle, when combined with weak Pareto, implies the rival utilitarian reward principle. ${ }^{16}$

\footnotetext{
${ }^{12}$ For overviews of the literature on compensation and responsibility, see Fleurbaey (2008), Fleurbaey and Maniquet (2011) and Roemer and Trannoy (2016). Fleurbaey (2008) pays particular attention to the comparison between liberal and utilitarian reward.

${ }^{13}$ Liberal reward was introduced into the economics literature by Bossert (1995), Fleurbaey (1994, 1995) and Bossert and Fleurbaey (1996).

${ }^{14}$ Utilitarian reward was proposed by Roemer (1993) and Van de gaer (1993). The term "utilitarian" refers to the sum-ranking aspect of the principle.

15 That liberal reward implies a preference for laissez-faire if all individuals have the same circumstances has been noted before: see, e.g., Fleurbaey (2008, p. 10). Further, observe that liberal reward is related to equal sacrifice. Restricting to social states in which total market income is at least as great as total disposable income, we obtain liberal reward from equal sacrifice by setting the common utility $u$ equal to the identity function.

${ }^{16}$ Example 1 suffices to illustrate that there exist social rankings that satisfy liberal reward and strong Pareto.
} 
Corollary 2 If a social ranking $R$ satisfies liberal reward and weak Pareto, then $R$ satisfies utilitarian reward.

We again end on a note of pessimism regarding the scope to strengthen liberal reward. Even a modest strengthening that recommends sacrificing an arbitrarily small amount of total disposable income in exchange for disposable income differences substantially closer to market income differences would clash with weak Pareto. $^{17}$

\section{Conclusion}

The economic literature has traditionally stressed the role of laissez-faire as an instrument for welfare maximization. Our results show the difficulties in treating the respect for laissez-faire outcomes as an end in itself. If the full Pareto principle is required, then no social ranking can satisfy the laissez-faire principle. If only weak Pareto is required, then there are possibilities, but these are very restricted. In cases where the social states differ in total disposable income, market incomes must be ignored and the social state with greater total disposable income must be chosen, leaving little room for libertarian values.

Open Access This article is licensed under a Creative Commons Attribution 4.0 International License, which permits use, sharing, adaptation, distribution and reproduction in any medium or format, as long as you give appropriate credit to the original author(s) and the source, provide a link to the Creative Commons licence, and indicate if changes were made. The images or other third party material in this article are included in the article's Creative Commons licence, unless indicated otherwise in a credit line to the material. If material is not included in the article's Creative Commons licence and your intended use is not permitted by statutory regulation or exceeds the permitted use, you will need to obtain permission directly from the copyright holder. To view a copy of this licence, visit http://creativecommons.org/licen ses/by/4.0/.

\section{References}

Arneson RJ (1989) Equality and equal opportunity for welfare. Philos Stud 56:77-93

Arneson RJ (1990) Liberalism, distributive subjectivism, and equal opportunity for welfare. Philos Public Aff 19:158-194

\footnotetext{
17 However, if we impose that the market income distribution $m$ is fixed, then there do exist social rankings that satisfy both full Pareto and this strengthening of liberal reward. As an example, consider a social ranking $R$ that applies the Kolm-Pollak social welfare function (Kolm 1976; Pollak 1971) to differences between disposable and market income. That is, there exists a real number $\alpha>0$ such that, for all social states $(x, m)$ and $\left(x^{\prime}, m\right)$ in $S$, we have $(x, m) R\left(x^{\prime}, m\right)$ if and only if $\sum_{i}-e^{-\alpha\left(x_{i}-m_{i}\right)} \geq \sum_{i}-e^{-\alpha\left(x_{i}^{\prime}-m_{i}\right)}$. See Bosmans and Öztürk (2021) on social rankings in this vein. Note that similar options are available in the context of the equal sacrifice principle. Incidentally, the above example illustrates that non-utility information, in this case the market incomes in $m$, can play an important role in a welfarist social ranking if this information does not vary across social states (see also Weymark 2017, p. 207).
} 
Bosmans K, Öztürk ZE (2021) Measurement of inequality of opportunity: a normative approach. J Econ Inequal 19:213-237

Bossert W (1995) Redistribution mechanisms based on individual characteristics. Math Soc Sci 29:1-17

Bossert W, Fleurbaey M (1996) Redistribution and compensation. Soc Choice Welf 13:343-355

Campbell DE, Kelly JS (2002) Impossibility theorems in the Arrovian framework. In: Arrow KJ, Sen AK, Suzumura K (eds) Handbook of social choice and welfare, vol I. North-Holland, Amsterdam

Cohen GA (1989) On the currency of egalitarian justice. Ethics 99:906-944

Dworkin R (1981a) What is equality? Part 1: equality of welfare. Philos Public Aff 10:185-246

Dworkin R (1981b) What is equality? Part 2: equality of resources. Philos Public Aff 10:283-345

Fleurbaey M (1994) On fair compensation. Theory Decis 36:277-307

Fleurbaey M (1995) Three solutions for the compensation problem. J Econ Theory 65:505-521

Fleurbaey M (2008) Fairness, responsibility, and welfare. Oxford University Press, Oxford

Fleurbaey M, Maniquet F (2011) Compensation and responsibility. In: Arrow KJ, Sen AK, Suzumura K (eds) Handbook of social choice and welfare, vol II. North-Holland, Amsterdam

Fleurbaey M, Tungodden B, Chang HF (2003) Any non-welfarist method of policy assessment violates the Pareto principle: a comment. J Polit Econ 111:1382-1385

Huemer M (2018) Is wealth redistribution a rights violation? In: Brennan J, van der Vossen B, Schmidtz D (eds) The Routledge handbook of libertarianism. Routledge, New York

Kaplow L, Shavell S (2001) Any non-welfarist method of policy assessment violates the Pareto principle. J Polit Econ 109:281-286

Kaplow L, Shavell S (2004) Any non-welfarist method of policy assessment violates the Pareto principle: reply. J Polit Econ 112:249-251

Kolm S-C (1976) Unequal inequalities I. J Econ Theory 12:416-442

Mill JS (1909) Principles of political economy, 7th edn. Longmans, Green and Co., London (originally published in 1848)

Musgrave RA (1959) The theory of public finance. McGraw-Hill, New York

Nozick R (1974) Anarchy, state, and Utopia. Blackwell, Oxford

Pollak RA (1971) Additive utility functions and linear Engel curves. Rev Econ Stud 38:401-414

Rawls J (1971) A theory of justice. Harvard University Press, Cambridge, Mass

Rawls J (1982) Social unity and primary goods. In: Sen AK, Williams B (eds) Utilitarianism and beyond. Cambridge University Press, Cambridge

Roemer JE (1993) A pragmatic theory of responsibility for the egalitarian planner. Philos Public Aff 22:146-166

Roemer JE, Trannoy A (2016) Equality of opportunity: theory and measurement. J Econ Lit 54:1288-1332

Rothbard M (1973) For a new liberty: the libertarian manifesto. Libertarian Review Foundation, New York

Rothbard M (1977) Power and market: government and the economy, 2nd edn. Sheed Andrews and McMeel, Kansas City

Suzumura K (2001) Pareto principles from inch to ell. Econ Lett 70:95-98

Suzumura K (2011) Welfarism, individual rights, and procedural fairness. In: Arrow KJ, Sen AK, Suzumura K (eds) Handbook of social choice and welfare, vol II. North-Holland, Amsterdam

Van de gaer D (1993) Equality of opportunity and investment in human capital. PhD thesis, Katholieke Universiteit Leuven

Weinzierl M (2014) The promise of positive optimal taxation: normative diversity and a role for equal sacrifice. J Public Econ 118:128-142

Weymark JA (2017) Conundrums for nonconsequentialists. Soc Choice Welf 48:269-294

Young HP (1987) Progressive taxation and the equal sacrifice principle. J Public Econ 32:203-214

Young HP (1988) Distributive justice in taxation. J Econ Theory 44:321-335

Young HP (1990) Progressive taxation and equal sacrifice. Am Econ Rev 80:253-266

Publisher's Note Springer Nature remains neutral with regard to jurisdictional claims in published maps and institutional affiliations. 